\title{
CONGENITAL DEXTROCARDIA WITH PATENT DUCTUS OVALE
}

\author{
NECROPSY AT NINE MONTIIS* \\ H. J. MORGAN, M.D. \\ TOLEDO, OHIO
}

In view of the rarity of congenital dextrocardia alone, as shown by the review of the literature recently published by Moffett and Neuhoff, ${ }^{1}$ this case is reported. As in almost all cases reported this patient suffered from congenital defect of the heart itself. Its occurrence in a girl and the opportunity for necropsy are interesting features.

\section{CASE REPORT}

Jean M., a girl, aged about 1 month, was brought to the Maternity and Children's Hospital for adoption, August 18, 1915.

On physical examination the baby was found to weigh 5 pounds 5 ounces and its length of body to be $18 \% / 4$ inches, circumference of head $13 \frac{1}{4}$ inches, of chest $11 \frac{1 / 2}{2}$ inches. The temperature was 99 , pulse 144 , respiration 40 .

The skin of the whole body was cyanotic, more marked over the face and hands. The respiration was rapid, with a sinking in of the suprasternal notch and epigastrium on inspiration, and an active movement of alae nasi. The conjunctivae were congested, but otherwise the eyes, ears, nose and throat were normal.

The respiration was wheezing and difficult, and most râles were perceptible over both lungs in front and at the back, but no other abnormalities of the lungs were present.

The apex of the heart was felt on the right side $6 \mathrm{~cm}$. to the right of the midsternal line at the fourth interspace; the right border at the fifth interspace was $5 \frac{1}{2} \mathrm{~cm}$., at the fourth interspace $6 \mathrm{~cm}$., at the third interspace $5 \frac{1}{2}$ $\mathrm{cm}$. to the right of the midsternal line; the left border was $1 \mathrm{~cm}$. to the left of the midsternal line at the fourth interspace, and the upper border was at the second interspace on the right side. At the first examination a distinct, rough, systolic murmur was heard, loudest at the apex, but more or less distinct over the whole cardiac area. It was not transmitted, and no thrill was felt.

Above the heart in the second interspace an area of dullness extending $3 \mathrm{~cm}$. to the left of the midsternal line was felt. This was taken to be the enlarged thymus.

The liver and spleen seemed to be in normal position. No bony changes and no clubbing of the fingers were present, and no other abnormalities could be detected. A roentgenogram taken at this time (Fig. 1) shows the correctness of the foregoing findings.

Blood examination showed hemoglobin 130 per cent. (Sahli), red cells $6,250,000$, white cells 9,200 , polymorphonuclears 47.5 per cent., large leukocytes 20 per cent., small leukocytes 32.5 per cent., with no abnormal red cells.

The thymic enlargement and the wheezing, bubbling character of the respiration suggested the possibility of thymic asthma, and so the baby was treated by Roentgen-ray exposures, as outlined in a report of cases of this disorder successfully treated by us, ${ }^{2}$ but no benefit followed.

Except for a gain of 4 pounds 14 ounces in the next eight and one-half months no marked changes occurred in her condition. While her color was

* Submitted for publication May 22, 1916.

1. Moffett and Neuhoff: Am. Jour. Dis. Child., 1915, x, 1.

2. Morgan and Dachtler: Surg., Gynec. and Obst., 1914, xix, 781. 
at times fairly good, she usualiy showed slight cyanosis of the face and hands, and when exposed to cold or lifted about, she became very deeply cyanosed.

The heart murmur heard at first examination was not heard again for about a month. It never became constant, and when heard it was never transmitted to the neck and no thrill was ever felt.

Death occurred May 2, 1916, when the girl was about 9 months of age, following two severe convulsions.

Necropsy.-When the chest was opened it was seen that the left lobe of the thymus was quite large, the tip being in the fourth interspace, the extreme left edge being $2 \frac{1}{2} \mathrm{~cm}$. to the left of the midsternal line.

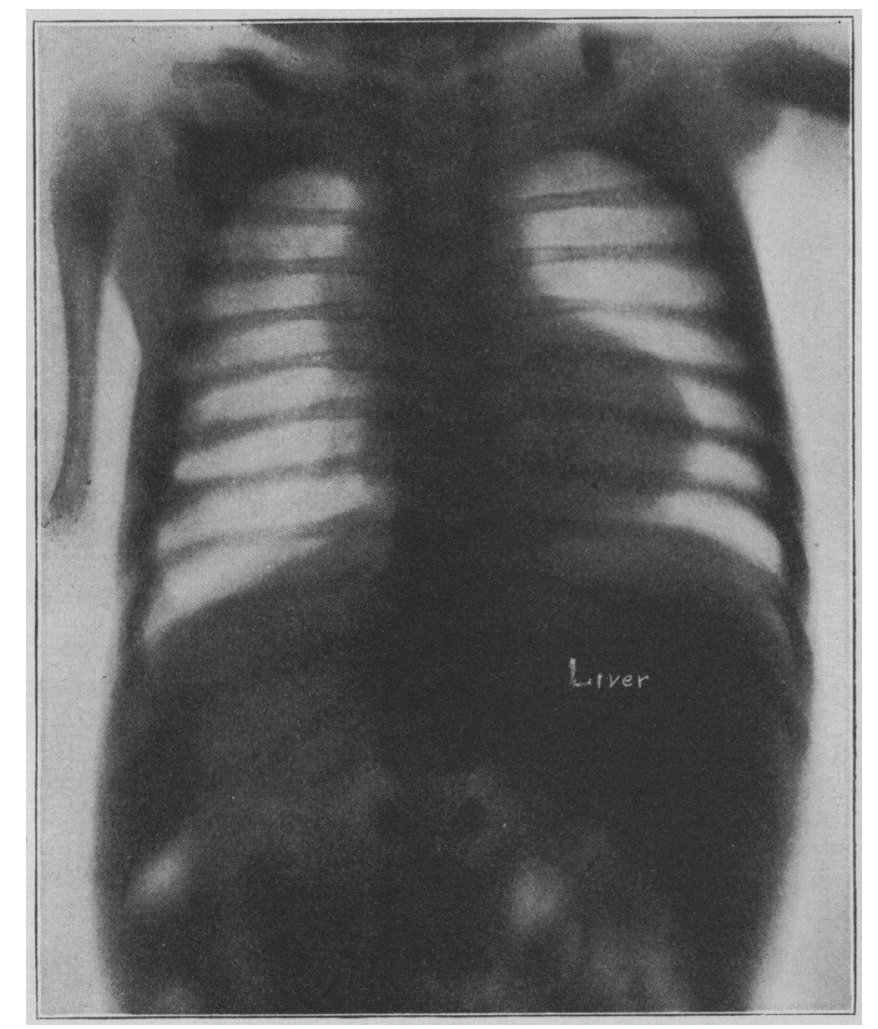

Fig. 1.--Roentgenogram showing dextrocardia.

The heart was on the right side, the lungs, including the lobar divisions, were normal. The liver, stomach and spieen were in normal position and without abnormalities. The pericardium contained 18 c.c. clear fluid. The heart was globular in shape, the walls of the left ventricle very thick, those of the right rather thin, with a muscular defect which showed as a dimple in the external surface, not extending through the wall. The heart valves were normal except for the patent ductus ovale. There was no interventricular defect. The large vessels leading off from the rather exaggerated aortic arch were in normal position.

Thanks are due to $H$. H. Dachtler for the Roentgen-ray work and to W. E. Mosely for the necropsy.

507 Nicholas Building. 